\title{
Avaliação de performances por ouvintes: um estudo com estudantes de licenciatura em música da FAMES
}

\author{
João Fortunato Soares de Quadros Júnior (UEMA, São Luiz, MA) \\ joaofjr@gmail.com \\ Mikely Pereira Brito (Faculdade de Música do Espírito Santo, Vitória, ES) \\ mikbrito@yahoo.com.br
}

\begin{abstract}
Resumo: Este estudo investigou a relação entre a variação de expressividade e a preferência de performances na opinião de ouvintes, tomando como objeto de estudo os estudantes do curso de licenciatura em música da FAMES. Partindo da premissa que correlaciona positivamente uma performance expressiva ao nivel de apreciação do ouvinte, este trabalho submeteu os estudantes a três performances distintas de uma mesma obra. Dessa maneira, cada performance considerada previamente por juizes independentes como de alta, média e baixa expressividade, recebeu um nivel de preferência atribuido por cada aluno e a premissa foi avaliada. Os estudantes também foram solicitados a indicar quais aspectos musicais eles consideram preponderantes na construção de uma performance musical expressiva. Os resultados apontam para uma relação direta entre o nivel de expressividade e a preferência de performance. Quanto aos aspectos musicais relacionados à expressividade, confirmam-se as associações feitas pelos ouvintes entre a expressividade na performance musical e as variações de dinâmica, intensidade, tempo, agógica, articulação, altura e timbre.
\end{abstract}

Palavras-chave: Expressividade; performance musical; preferência musical.

\section{Evaluation of performances for listeners: a study with undergraduate music students from FAMES}

Abstract: This study investigated the relationship between expressivity variation and performances preference in the opinion of listeners, taking as study object undergraduate music students from FAMES. Assuming that an expressive performance and the listener's appreciation level are positively correlated, this paper submitted the students to three different performances of the same piece. Thus, each performance, previously considered by independent judges as having a high, medium and low expressivity, received a preference level given by each student, and the premise was evaluated. Students were also requested to indicate which musical aspects they consider preponderant on the construction of an expressive music performance. The results indicate a direct relation between the level of expressivity and the performance preference. About the musical aspects most related to musical expression, are confirmed the associations made by listeners between expressivity in musical performance and changes in dynamic, intensity, duration, time variation, articulation, timbre and time.

Keywords: Expressivity; musical performance; musical preference.

\section{A construção da performance musical e sua relação com o ouvinte \\ A performance musical é um processo de realização sonora onde o músico comunica aos ouvintes sua mensagem, interpretando determinado texto ou idéia musical (PALMER, 1997; SLOBODA, 2008; SWANWICK, 2003). Numa visão mais ampla, SLOBODA (2008) a}

define como aquela que abrange qualquer manifestação musical, incluindo um canto improvisado de uma criança, um canto de uma canção folclórica ou mesmo uma dança.

A construção da performance envolve diversos aspectos a serem trabalhados pelo intérprete, sendo um deles o estudo da partitura, observando-se as indicações do compositor. 
Além disso, ocorrem também etapas de pesquisa e análise da peça, onde são adquiridos conhecimentos teóricos sobre a obra a ser executada, tais como o período em que ela foi composta, aspectos das práticas interpretativas desse período, características estilísticas do compositor, dentre outros. Esses conhecimentos irão influenciar o executante em sua performance, contribuindo para uma melhor interpretação da obra (WINTER; SILVEIRA, 2006).

Embora a partitura contenha informações essenciais que orientam o intérprete no preparo de sua performance musical, nem sempre são explicitados nela todos os elementos necessários para uma boa execução. PALMER (1997) afirma que as indicações de intensidade e dinâmica são indeterminadas, constituindo ambiguidades na notação, permitindo assim uma liberdade considerável do músico nas suas decisões interpretativas.

É importante ressaltar que o performer deve ter claro em mente o que pretende transmitir com sua execução musical. WOODY (2000) afirma que o objetivo final de um intérprete é comunicar algo ao ouvinte através de sua performance. Para isso, é primordial considerar que a maneira de ouvir e interpretar uma música varia de um ouvinte para o outro, podendo uma mesma interpretação causar diferentes reações em diferentes ouvintes. De acordo com JOURDAIN (1998, p.326), isso ocorre porque:

\footnotetext{
Cada um de nós tem seu próprio estilo de ouvir, uma tendência a prestar atenção a certas características da música, deixando outras de lado. Algumas pessoas sentem uma atração especial pela melodia, outras por harmonia, métrica, fraseado ou forma. [...] Não existe nenhuma tipologia rígida de ouvintes.
}

0 autor chama isso de preferência cognitiva, que corresponde a uma inclinação por certos tipos de música. Ainda segundo JOURDAIN (1998), os ouvintes usualmente não se acomodam na audição de canções simples. Pelo contrário, à medida que envelhecem, as pessoas passam a preferir músicas mais complexas, o que indica que a preferência cognitiva não é estática, mas sofre variações à medida que os ouvintes se envolvem com a escuta musical.

Levando-se em consideração aspectos mais gerais que envolvem o ouvinte e a performance musical, alguns outros fatores interferem nessa relação. Nem sempre a predileção por uma interpretação está relacionada apenas a aspectos musicais inerentes àquela peça. Existem outros quesitos a serem considerados. THOMPSON (2007) realizou um estudo para determinar esses quesitos envolvidos em uma performance ao vivo. Ele considera a existência de fatores que interferem na predileção antes e durante a audição. Para cada momento, ele divide esses fatores em três componentes.

Para o caso dos componentes envolvidos antes da audição, o primeiro está relacionado à música propriamente dita. Eles dizem respeito à expectativa do ouvinte, à familiaridade com o repertório, à presença de amigos no momento da escuta, à familiaridade com o instrumento tocado e à preferência musical do ouvinte. 0 segundo componente diz respeito ao estado emocional do ouvinte antes da escuta. Já o terceiro envolve a familiaridade do ouvinte com o local de execução da performance assim como com o performer.

Quanto aos componentes envolvidos durante a performance, o primeiro relaciona-se com o envolvimento do ouvinte com a execução. Nesse contexto estão, dentre outros, o julgamento da interpretação dada pelo músico por parte do ouvinte e o envolvimento emocional deste com a execução. 0 segundo componente trata do que ele denominou de dynamic modifiers, aspectos musicais e extra-musicais que interferem na atenção do ouvinte e que podem ser modificados à medida que a performance se desenvolve. São eles: a execução tecnicamente correta da peça, a interferência de sons externos, o local onde 0 ouvinte está sentado, a duração da peça, dentre outros. Os dynamic modifiers podem influenciar positivamente ou negativamente a apreciação da música pelo ouvinte. Por fim, o terceiro componente, denominado background modifiers, corresponde a variáveis que podem tirar a atenção do ouvinte e provavelmente não serão mudadas durante a performance. Aqui pode ser citado o estado emocional do performer, a peça em si e até mesmo a maneira com a qual o músico está vestido.

Dessa forma, pode-se constatar que são diversas as variáveis envolvidas na determinação da preferência por uma performance musical, abrangendo aspectos tanto musicais quanto extra-musicais. A maneira como essas variáveis são relacionadas e se manipulam, assim como a maior ou menor incidência e influência delas na audição, dependem da estrutura musical, do contexto e dos ouvintes, e, portanto, podem conter grandes variações de um indivíduo para outro. PALHEIROS (2006, p.309) afirma que:

As diferentes maneiras de ouvir e 'usar' música podem estar relacionadas com as funções da música, e podem depender de caracteristicas pessoais do ouvinte (idade, formação musical), da situação (intenção de ouvir, atenção) e do contexto (físico, social, cultural, educativo).

Sendo assim, percebemos o quão complexa é a busca pela interpretação 'adequada', tornando-se importante considerar todos os aspectos apontados pela literatura como influentes no modo de se escutar música, na busca de construir uma performance que contenha uma menor incidência de variáveis de influência, possibilitando a transmissão mais aproximada da idealizada pelo intérprete.

\section{Música e expressividade}

$\mathrm{Na}$ construção da performance, é fundamental que 0 intérprete se preocupe não apenas com a técnica, mas também com a expressividade em sua execução. Segundo FRANÇA (2001), afirmar que a habilidade técnica é o que caracteriza o músico distorce a essência da musicalidade. Ela comenta que a performance instrumental vem ao longo dos anos dando ênfase ao desenvolvimento técnico instrumental em detrimento de um fazer musical mais 
expressivo, consistente e musicalmente significativo. A autora defende que a escolha de uma peça a ser trabalhada não deve ser feita visando a sua dificuldade técnica, mas sim as oportunidades que ela oferece na tomada de decisões criativas e na exploração da expressão musical.

A expressividade na música se relaciona com elementos musicais que "dependem de uma reação pessoal e variam entre diferentes interpretações" (SADIE, 1994, p.306). Um levantamento bibliográfico sobre expressividade musical é feito por LOUREIRO (2006), reunindo diversas publicações da área, tais como: estudos comparativos entre performances, visando identificar semelhanças e diferenças entre elas; pesquisas relacionadas à determinação das intenções expressivas de diferentes intérpretes, a fim de verificar se elas são percebidas pelos ouvintes; investigações sobre o impacto emocional da performance no ouvinte e sua relação com a expressividade; estudos para quantificar a expressividade e gerar modelos para a expressividade musical na performance, propondo regras e caminhos a serem seguidos pelo performer; pesquisas que tratam da modelagem de aspectos específicos da performance visando uma maior expressividade, tais quais as correlações entre o ritardando final e o movimento humano, a duração de notas de appogiaturas, o vibrato, a articulação, desvios de tempo e de intensidade, dentre outros.

É importante abordar a maneira como um intérprete modela a sua performance a fim de torná-la mais expressiva. Esta, num sentido amplo, caracteriza-se por utilizar da comunicação não-verbal (DA SILVA et al., 2000). No caso da performance corporal, o corpo é o instrumento através do qual o músico comunica a expressividade utilizando movimentos e gestos. De forma semelhante, na performance musical, o músico utiliza a voz ou o instrumento musical para comunicar sua expressão.

A comunicação da expressividade, assim como qualquer outra forma de comunicação, depende de quem comunica e de quem ouve, ou seja, do performer e do ouvinte. Não existe um modelo ideal de performance expressiva. Porém, existem maneiras do intérprete manipular elementos expressivos com maior ou menor intensidade e quantidade, de maneira a obter interpretações mais ou menos expressivas de uma mesma peça (LOUREIRO, 2006; PALMER, 1997; WOODY, 2000). DE POLI (2004) esclarece que a contribuição do intérprete para a comunicação da expressividade tem duas facetas. Uma delas é esclarecer a mensagem do compositor no que se refere à estrutura musical e a outra é acrescentar sua interpretação pessoal à peça.

Considerando-se os aspectos musicais mais abordados por pesquisas relacionadas à expressividade, pode-se dizer que os mais citados são agógica, altura, articulação, dinâmica, intensidade, tempo e timbre (BRESIN; BATTEL, 2000; CANAZZA et al., 2003; DE POLI et al., 1998; DE POLI, 2004; LISBOA; SANTIAGO, 2006; LOUREIRO, 2006; PELLON, 2008; ROBATTO, 2004; SWANWICK, 2003; TODD, 1992; WOODY, 2000). A manipulação desses aspectos ocorre em qualquer performance. A diferença entre uma baixa, média e alta expressividade está na frequência de ocorrência ao longo da performance e na magnitude de cada elemento. Essas são decisões a serem tomadas pelo intérprete baseando-se em suas vivências e também no estilo da peça e são geralmente percebidas pelos ouvintes.

\section{A avaliação da performance}

$A$ avaliação se constitui numa ação frequente em música, estando presente no momento da escolha do que ouvir, qual repertório tocar ou utilizar nas aulas com os alunos. Tal procedimento ocorre, em sua maioria, de maneira informal, não necessitando de relatórios escritos para justificar essas decisões (SWANWICK, 2003). Esta fase é chamada por Swanwick de avaliação por filtragem. FIREMAN (2007) argumenta que na filtragem não há uma preocupação com a precisão, mas se avalia considerando a experiência vivida anteriormente.

Outro tipo comum consiste na avaliação por comparação. Ela pode ser interpessoal, comparando-se as ações do avaliado hoje e no passado, ou intrapessoal, onde são feitas comparações entre pessoas diferentes. Um processo avaliativo eficaz é realizado com o estabelecimento de critérios coerentes de julgamento. Nas diferentes atividades do fazer musical, esses critérios nem sempre são fáceis de serem estabelecidos porque a música é muitas vezes vista como uma atividade de difícil mensuração (EMRICH; BARRENECHEA, 2004; HENTSCHKE; DEL BEN, 2003).

No que se refere à avaliação da performance, ela tem ainda sido vista como um processo de mensuração do desempenho técnico do performer (OLIVEIRA; TOURINHO, 2003; SWANWICK, 2003). Essa visão é questionada por pesquisadores que defendem que a habilidade técnica é importante, porém não pode ser tratada como o único parâmetro de avaliação (FRANÇA; SWANWICK, 2002; FRANÇA, 2004; TOURINHO, 2001). Quanto ao julgamento por parte do ouvinte, ele não ocorre necessariamente levando-se em consideração a habilidade técnica do performer. LOUREIRO (2006, p.7-8) afirma que:

\footnotetext{
Diferenças entre performances são percebidas com uma clareza surpreendente, mesmo por não especializados, o que faz com que uma performance tecnicamente perfeita, mas inexpressiva, seja quase sempre menos apreciada que uma interpretação expressiva da mesma partitura, ainda que contenha alguns erros ou imprecisões.
}

Ao abordar a maneira como o ouvinte avalia uma execução musical, deve-se entender previamente quais os critérios geralmente utilizados para tal. BOYLE (1987) afirma que o julgamento de uma performance musical é baseado nas sensações que a música transmite e em como elas são processadas pelo cérebro. A avaliação de uma mesma performance pode ser diferente entre um indivíduo e outro. Alguns se prendem à análise de aspectos estritamente musicais, outros abordam também aspectos extra-musicais. Outros ainda se atentam para aspectos emocionais despertados pela interpretação. 
Outros fatores envolvidos na avaliação da performance são a preferência cognitiva e os aspectos musicais e não musicais envolvidos na performance. É importante salientar também a relação entre a avaliação e a preferência musical do ouvinte. A preferência musical é identificada nas pessoas pela música que decidem ouvir, pelos álbuns que optam por comprar e/ou pelos concertos que decidem assistir (QUADROS JR, 2009). Ela é construida ao longo da vida e pode sofrer mudanças. No entanto, a adolescência é um período crucial na sua formação (ANDREU, 2009). Nesse período, segundo JOURDAIN (1998), a preferência por um estilo musical é fixada, assim como a forma de ouvir música. Essa forma passa então a ser aplicada a todo tipo de audição e irá interferir em qualquer julgamento de aceitação ou rejeição de um produto musical. É fato que essa fixação pode ser modificada, dependendo de como 0 ouvinte passa a se relacionar com a música e se posicionar em relação às influências que recebe. Isso porque, como afirma QUADROS JR (2009), a preferência musical pode ser formada e desenvolvida de maneira autônoma ou de maneira induzida. No primeiro caso, o indivíduo escolhe de maneira consciente o que quer ouvir. Já no segundo caso, o indivíduo é conduzido à audição de determinado repertório ou estilo musical pelo meio ou por outros. Essa condução pode vir de diversas influências, destacando dentre elas os meios de comunicação - rádio, televisão e internet.

Com essas discussões, buscou-se relacionar a performance musical nos processos de escuta musical e avaliação, discutindo aspectos envolvidos na construção da performance, na maneira de transmissão da expressividade ao ouvinte, bem como na elaboração dos critérios de avaliação da expressividade e de indicação da preferência de performances.

\section{Metodologia}

Esta pesquisa teve uma abordagem quanti-qualitativa, caracterizada pela utilização de técnicas estatísticas para analisar e classificar os dados coletados, assim como a análise qualitativa das respostas abertas (DA SILVA; MENEZES, 2001).

Foi escolhido como universo de pesquisa a Faculdade de Música do Espírito Santo - FAMES, por se tratar da instituição de ensino superior em música com maior relevância no Estado.

A pesquisa foi realizada com alunos do curso de licenciatura em música da referida faculdade, contemplando estudantes de todos os períodos, abarcando os turnos matutino e noturno. Estes alunos foram escolhidos de forma conveniente, obedecendo aos seguintes critérios:

- Presença no momento da coleta dos dados;

- Concordância em participar da pesquisa.

Como instrumento de coleta de dados foi utilizado um questionário elaborado especificamente para essa pesquisa, constituido de perguntas de múltipla escolha sobre a preferência de performances e sobre os indicadores de expressividade que mais influenciam na elaboração/avaliação de uma performance mais ou menos expressiva. Na questão sobre a indicação da preferência, foi solicitado que os participantes assinalassem para cada performance ouvida uma entre as opções: Detestei, Não gostei, Indeciso, Gostei e Gostei muito.

Já para a investigação da influência dos indicadores de expressividade, solicitou-se a indicação da valoração de cada indicador obedecendo a uma escala Likert de 1 a 5, na qual 1 equivalia a Nenhuma influência e 5 equivalia a Altíssima influência.

0 questionário também continha questões nas quais os estudantes indicaram qual performance eles mais gostaram, qual a que menos gostaram, qual a performance mais expressiva e qual a menos expressiva. Além disso, contava com uma seção para que os estudantes justificassem as suas escolhas de maneira sucinta.

\section{1 - Procedimento}

Para essa pesquisa foi selecionada a música Can you feel the love tonight, de Elton John. Esta escolha se deu a partir da sugestão do intérprete participante da pesquisa. A música foi então executada de acordo com as três performances sugeridas: alta, média e baixa expressividade. A construção das performances se deu segundo as indicações trazidas no referencial teórico, sendo o nível alto de expressividade aquele no qual o performer explora uma maior variação na manipulação dos elementos expressivos (LOUREIRO, 2006). Dessa maneira, o nível baixo se referiu a uma performance que apresentasse pouca ou nenhuma variação na manipulação dos elementos expressivos. Por fim, a performance com nivel médio de expressividade foi construida a partir da manipulação dos elementos expressivos de maneira conveniente para o performer.

\subsection{1 - Gravação das performances}

Apósa seleção e o arranjo da música, as performances foram gravadas por um pianista escolhido pelos pesquisadores. Para esta gravação foi solicitado ao intérprete que tentasse tocar a música de distintas maneiras, utilizando recursos para obter diferentes tipos de performances com relação à expressividade. Assim sendo, ficou estabelecido como recursos de expressividade a utilização do pedal e variações significativas na dinâmica, intensidade, tempo, agógica, articulação, altura e timbre. Com isso, para as performances menos expressivas o intérprete buscou evitar a utilização de tais recursos e, por outro lado, para as mais expressivas, tentou explorá-los com exaustão. Dessa forma, o pianista executou a música sete vezes de forma a se obter uma variedade de performances com alta, média e baixa expressividade. Essas as gravações foram apresentadas a uma banca examinadora (juizes independentes) para que avaliassem, a partir de uma escala Likert de 1 (nível mínimo de expressividade) a 5 (nível máximo de expressividade) cada performance 
ouvida. Realizado o cálculo da média dos valores obtidos, a performance que obteve menor média foi considerada como de baixo nível de expressividade, bem como a que obteve maior média correspondeu à performance com alto nivel de expressividade. A gravação de nível médio correspondeu àquela que obteve média mais próxima de 3. As performances selecionadas pela banca examinadora apresentaram o mesmo nível de expressividade idealizado pelo performer no momento de construção das mesmas.

\subsection{2 - Teste piloto}

Antes da aplicação do questionário, foi realizada uma sessão de pré-teste com uma amostra reduzida de estudantes de licenciatura em música da faculdade para verificação da objetividade do questionário, sendo a amostra composta de quatro alunos escolhidos de forma conveniente. Dessa maneira, foi apresentado aos estudantes o questionário $e_{\text {, }}$ em seguida, a audição das três performances foi autorizada. Por solicitação dos estudantes, todas as performances foram ouvidas duas vezes.

\subsection{3 - Teste}

A aplicação dos questionários foi então realizada em todas as turmas do curso de Licenciatura. Explicadas as normativas que direcionava a aplicação, os questionários foram distribuídos e lidos, com a intenção de sanar possiveis dúvidas sobre o instrumento de coleta de dados. Seguindo a sugestão apontada durante o pré-teste, cada performance foi executada duas vezes, obedecendo a sequência estabelecida previamente. Buscando amenizar possiveis fatores que exercem influência no momento da escuta, optou-se por alterar a ordem de audição entre uma sala e outra, sendo utilizadas as seguintes combinações:

- $1-3-2$

- $2-3-1$

- $1-2-3$

- $3-2-1$
Onde:

1 = Nivel baixo de expressividade

2 = Nível médio de expressividade

3 = Nivel alto de expressividade

Essas combinações foram obtidas pelo procedimento da análise combinatória, utilizando-se a permutação simples. Depois de respondidos, os questionários foram recolhidos e organizados por período e turno.

\section{Resultados}

Para a análise das respostas dos questionários foi utilizado o software Microsoft Office Excel 2007, organizandose os resultados em gráficos estatísticos desenvolvidos no software supracitado. Dentre os diferentes tipos de análises possíveis, decidiu-se utilizar a estatística descritiva com cálculos de frequências, porcentagens e modas. Essa análise foi realizada observando-se a ordem das questões constantes no questionário. Os resultados foram estruturados em função das duas grandes categorias que compreendem o questionário:

- Relação entre expressividade e preferência;

- Aspectos musicais relacionados à expressividade na performance.

\section{1 - Valoração das performances}

A partir dos dados do Ex.1, é possível extrair algumas informações importantes:

- A performance 1, correspondente à performance menos expressiva, obteve o maior número de respostas "não gostei";

- A performance 2, correspondente à performance com média expressividade, obteve o maior número de respostas "gostei";

- A performance 3, correspondente à performance mais expressiva, obteve o maior somatório de respostas "gostei muito".

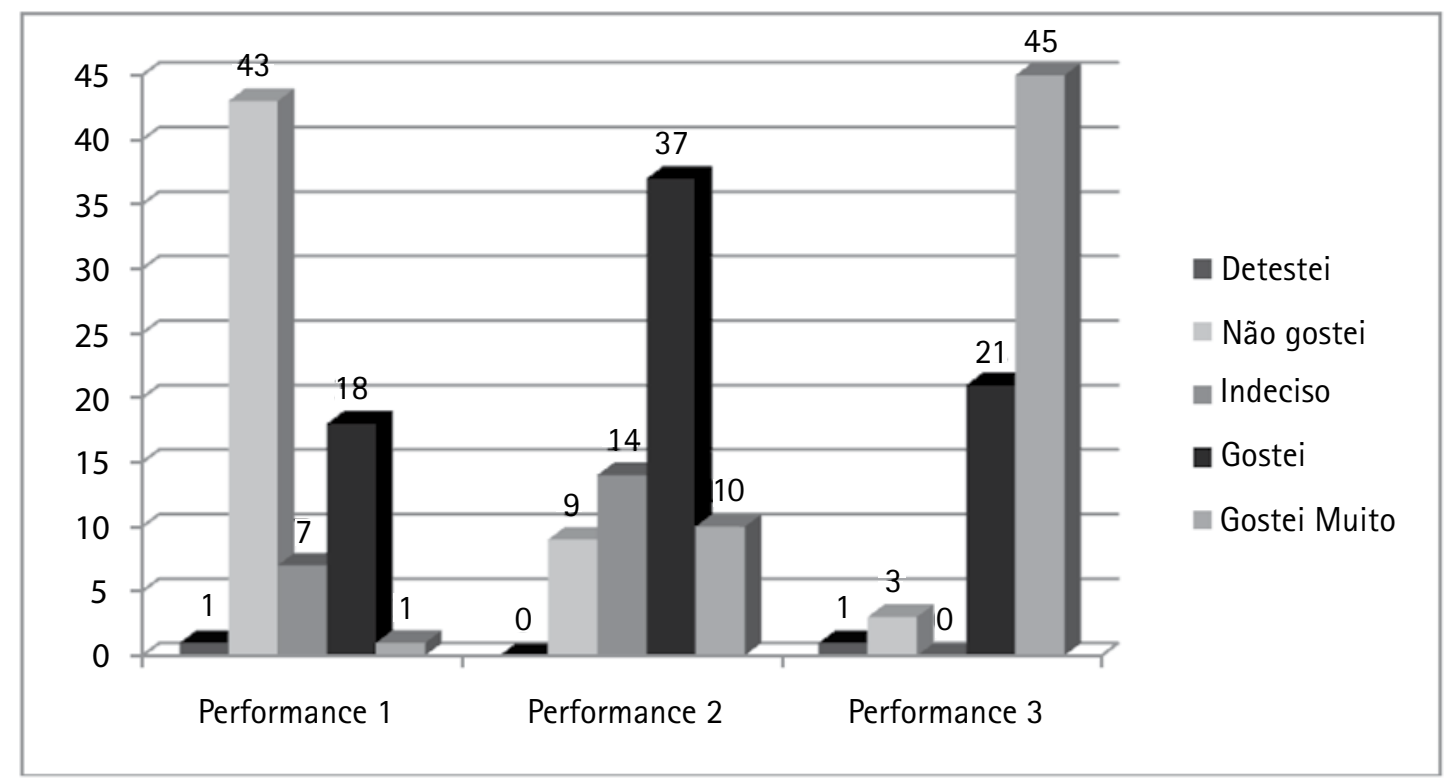

Ex.1 - Frequência das respostas referentes à valoração das performances escutadas. 
Dessa maneira, é possivel afirmar que a categorização estabelecida pelos juizes independentes e corroborada no pré-teste foi mais uma vez comprovada nas respostas dos alunos participantes.

\section{2 - Relação entre a expressividade e a preferência das performances}

Os resultados que seguem foram obtidos com as respostas das questões que investigaram a performance que os participantes mais gostaram, a que menos gostaram e qual a mais e menos expressiva.

Pode-se observar que $80 \%$ dos estudantes preferiram a performance 3 (equivalente à mais expressiva) (Ex.2), configurando assim a maioria das opiniões obtidas. Observa-se resultado semelhante para a performance que eles menos gostaram, indicada por 78,57\% dos estudantes como a performance 1 (Ex.3).

Em relação à indicação das performances "mais expressiva", "expressividade média" e "menos expressiva", foi observado que 90\% dos estudantes apontou a performance 3 como a mais expressiva (Ex.4), confirmando a categorização determinada pelos juízes independentes e com o pré-teste. Nenhum participante considerou a performance 1, correspondente à menos expressiva, como sendo a mais expressiva. Isso nos leva a concluir que $4,29 \%$ dos participantes preferem a performance menos expressiva, porém não a consideram como a mais expressiva. Ainda, 80\% dos participantes apontou a performance 1 (equivalente à menos expressiva) como tal (Ex.5).

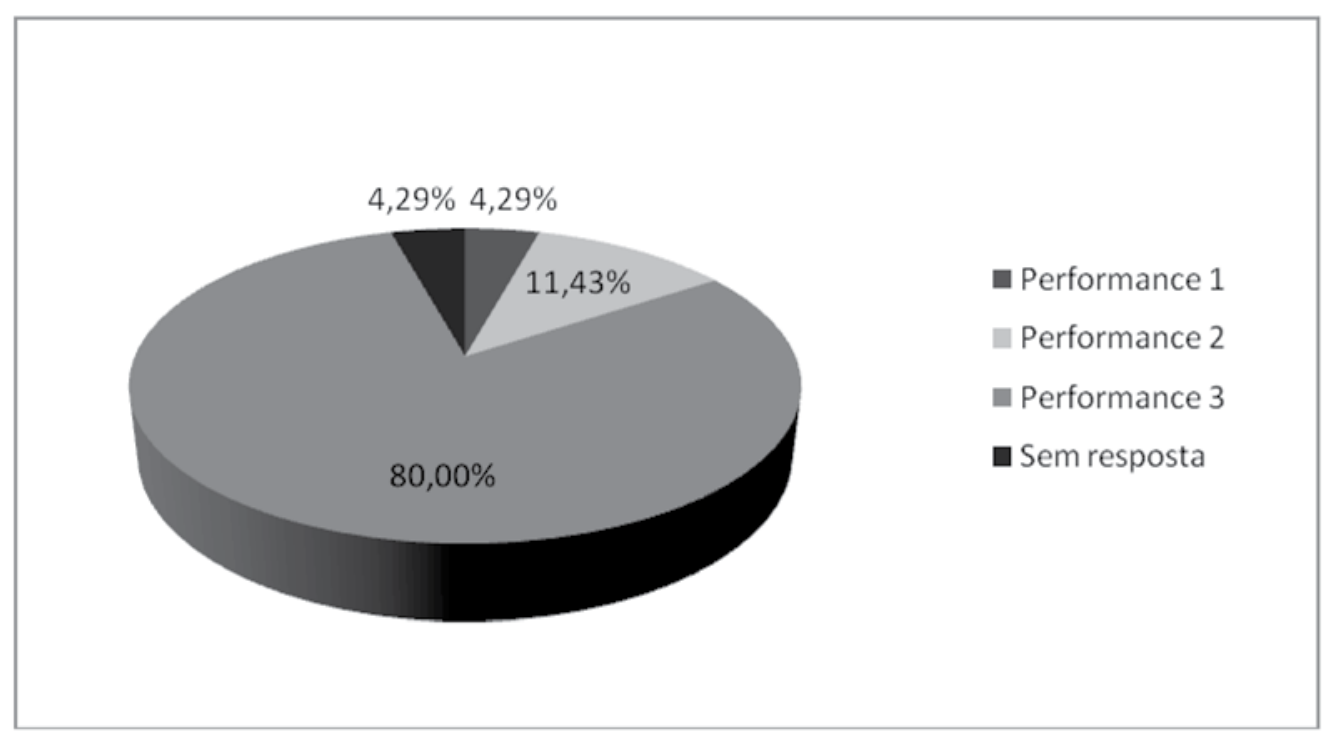

Ex. 2 - Porcentagem de respostas referentes à performance que mais gostaram.

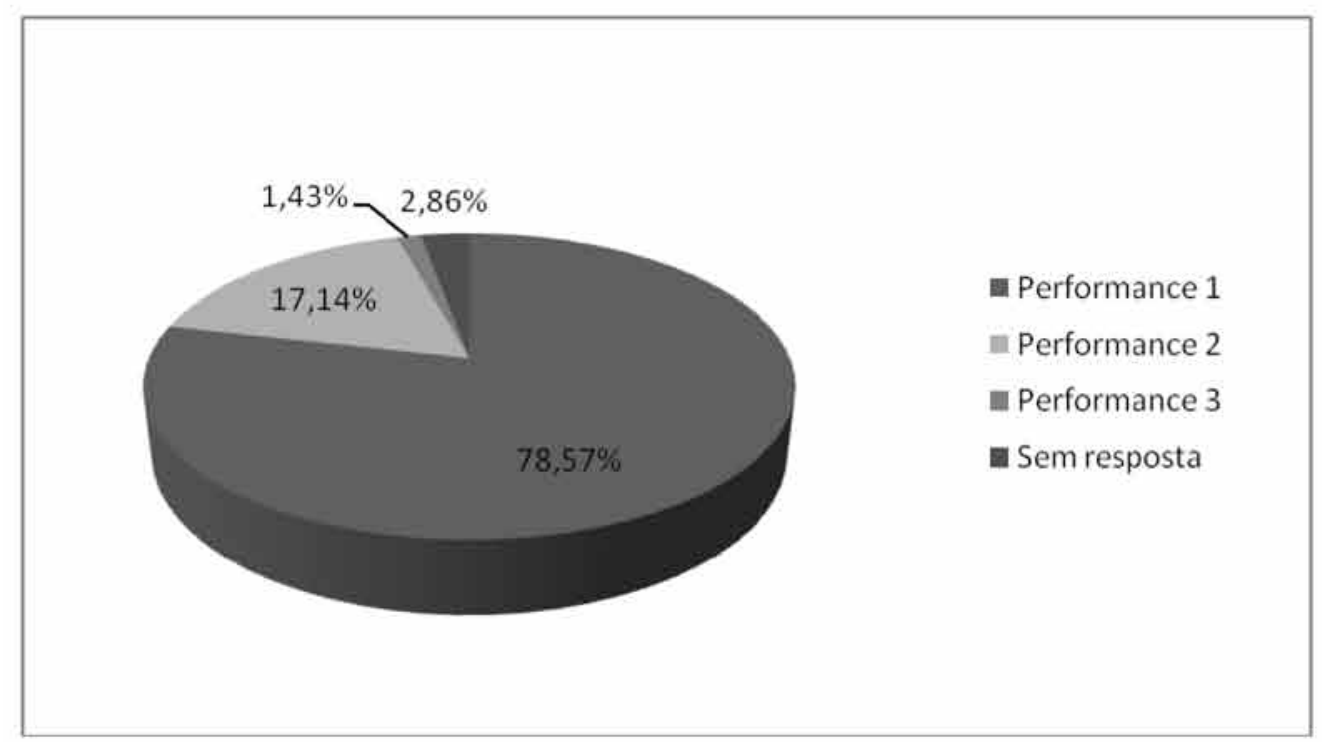

Ex. 3 - Porcentagem de respostas referentes à performance que menos gostaram. 


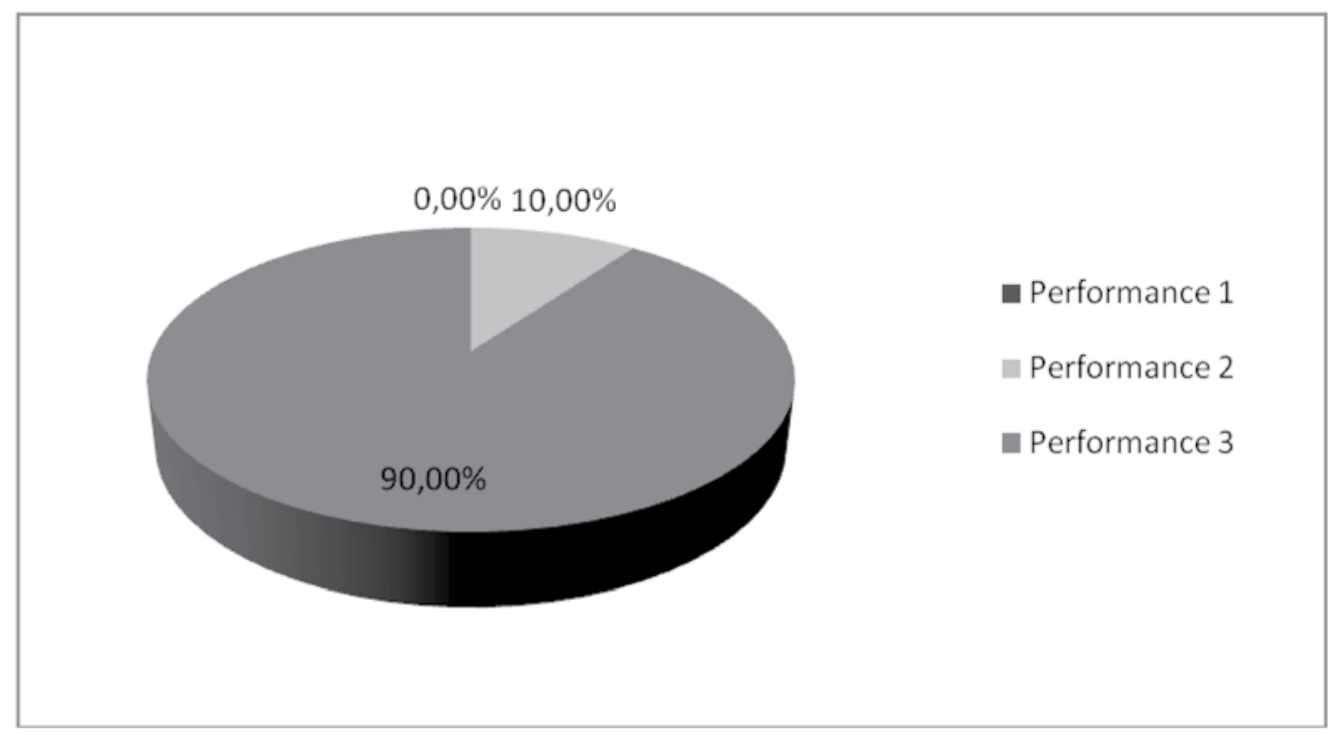

Ex. 4 - Porcentagem de respostas referentes à eleição da performance mais expressiva.

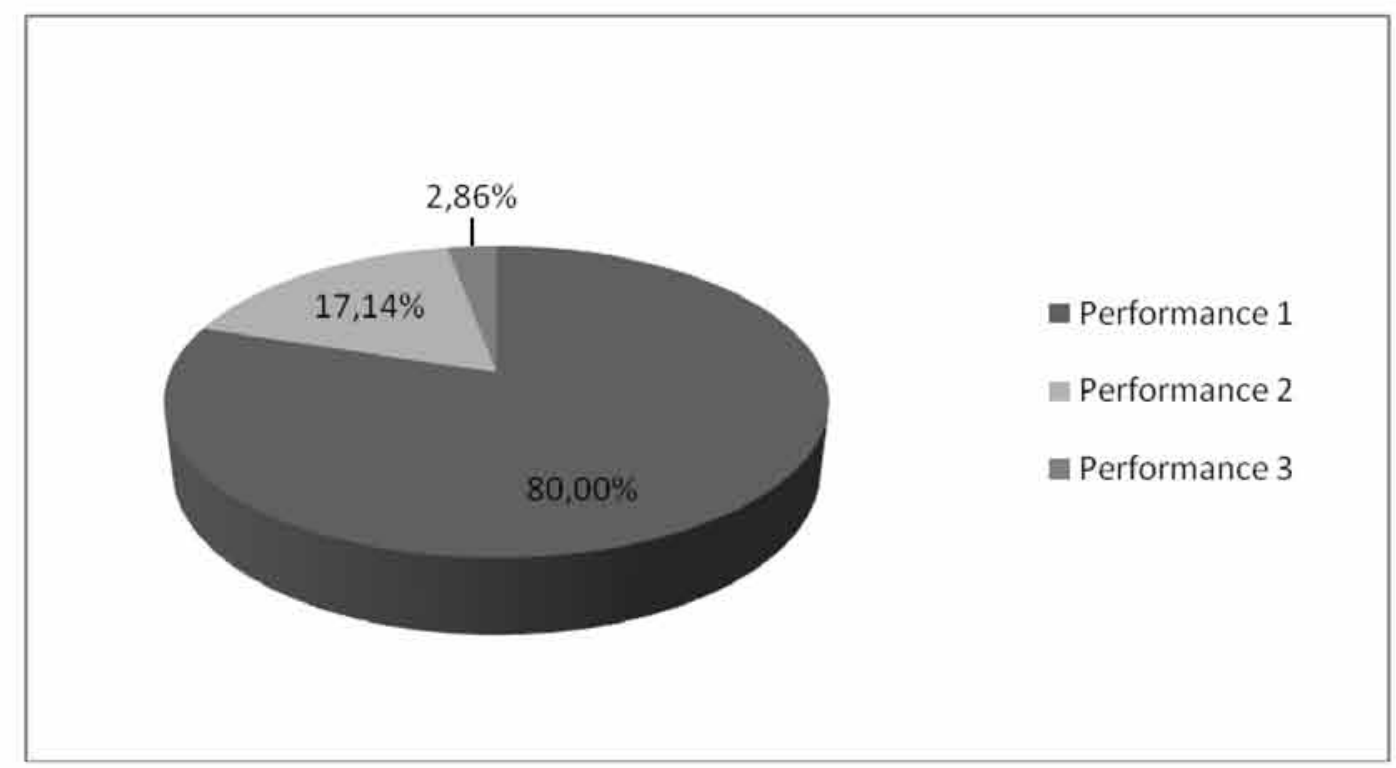

Ex. 5 - Porcentagem de respostas referentes à eleição da performance menos expressiva.

\section{3 - Análise dos itens de resposta aberta}

Uma questão de resposta aberta do questionário da pesquisa solicitava aos estudantes que apontassem quais os aspectos musicais considerados como fundamentais para a obtenção de uma performance musical expressiva. No gráfico 6 abaixo são ilustrados os aspectos constantes nas respostas e suas respectivas frequências.

Observa-se que o item "dinâmica" apresentou maior incidência (24\%), seguido dos itens "timbre" (9\%), "intensidade" (8\%) e "articulação" (7\%) (Ex.6). Destacase ainda a presença do item "sentimento", com incidência de $5 \%$, elemento não diretamente relacionado a aspectos musicais de uma performance.

\section{4 - Aspectos musicais relacionados à expressividade na performance}

$\mathrm{Na}$ sequência, são expostos os resultados obtidos da análise dos aspectos musicais que mais influenciam na obtenção de uma performance musical expressiva. Os dados analisados nessa seção foram extraídos da questão do questionário que solicitava que os estudantes respondessem qual a influência de cada aspecto musical relacionado na expressividade de uma performance, 
tendo como opções as respostas "nenhuma influência", "pouca influência", "média influência", "alta influência" ou "altíssima influência".

A partir do cálculo da moda, pode-se observar que, segundo a opinião dos estudantes pesquisados, os aspectos que mais influenciam são: "dinâmica", "altura", "articulação", "intensidade" e "timbre". Os aspectos indicados como de menor influência foram "agógica" e "tempo" (Ex.7). Ressalta-se ainda que nenhum dos aspectos relacionados se enquadrou nas categorias "nenhuma influência" e "pouca influência".

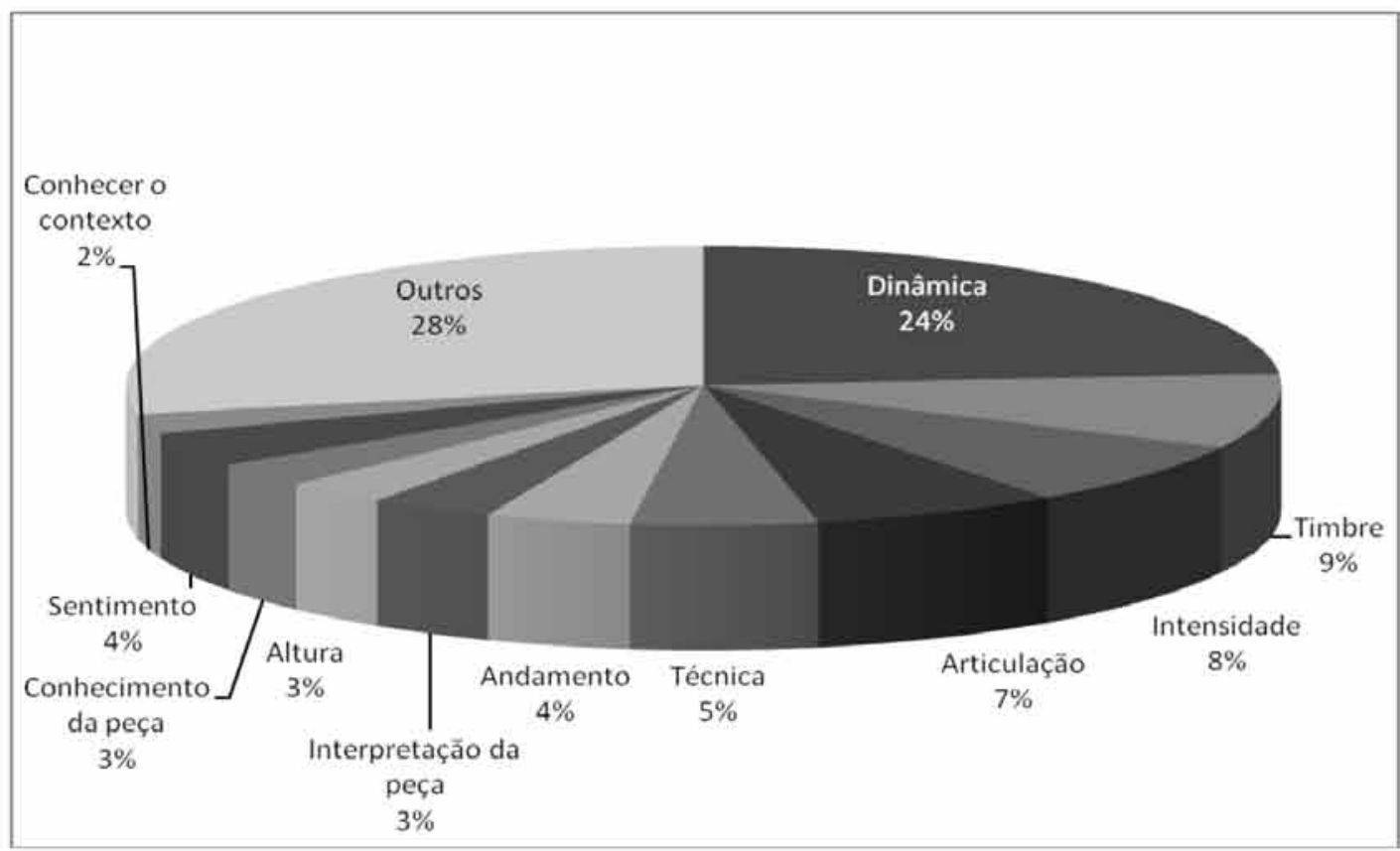

Ex. 6 - Porcentagem de respostas referentes a aspectos musicais relacionados à expressividade.

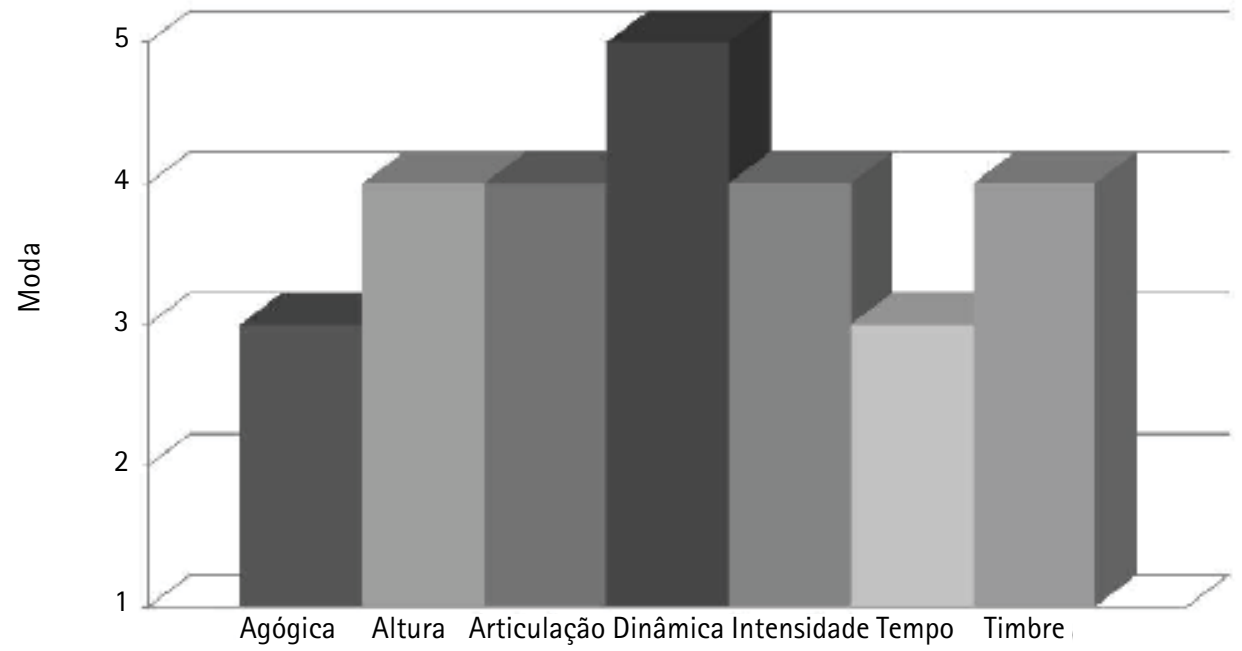

Ex. 7 - Valoração dos indicadores de expressividade apontados pela literatura. 


\section{Conclusões}

Este trabalho teve o objetivo de verificar qual a relação entre a variação de expressividade e a preferência de performances na opinião de ouvintes. Dessa forma, a partir dos dados coletados da amostra estudada, foi possivel constatar que a maioria dos ouvintes dessa pesquisa demonstrou preferência por performances que apresentam uma maior manipulação dos elementos expressivos, caracterizadas como performances mais expressivas. Em complementação a essa constatação, observa-se também que a maioria dos estudantes afirmou não gostar da performance menos expressiva. Esses resultados confirmam a afirmação de LOUREIRO (2006), que argumenta que os ouvintes em geral apreciam mais as performances mais expressivas.

Dentro das justificativas apresentadas para gostar ou não de uma performance, encontram-se diferentes abordagens. Alguns estudantes citaram aspectos estritamente musicais, outros comentaram sobre o apreço pela música ouvida (citando aspectos relacionados ao gosto pessoal e à preferência musical), alguns afirmaram que a preferência se deu pelas emoções despertadas, e também foram feitas algumas relações entre a preferência de performance e os aspectos ligados à técnica do performer, à criatividade e à expressividade transmitida ou não por ele.

A maioria das respostas obtidas coincidiu com as classificações atribuídas pelos membros da banca examinadora em relação às escolhas das performances mais expressiva, com média expressividade e menos expressiva. Esse fato é explicado pelas características de cada performance. Aquela pré-determinada como menos expressiva foi construída pelo intérprete sem a utilização dos pedais do piano e sem variações significativas dos elementos expressivos, tais como a agógica e a dinâmica. A não utilização dos pedais resultou em uma performance com poucas variações de intensidade e articulação, além de causar uma alteração no timbre devido à ausência de alguns harmônicos (SANTOS; CORVISIER, 2007). Em contrapartida, na construção da performance determinada como mais expressiva, foram exploradas as variações de dinâmica, intensidade, tempo, agógica, articulação, altura e timbre. $\mathrm{Na}$ performance com média expressividade, essas variações foram utilizadas de maneira randômica em trechos de maior relevância para os pesquisadores e o intérprete. Dessa maneira, são confirmadas as pesquisas de WOODY (2000), LOUREIRO (2006) e PALMER (1997), que relatam ser possivel ao performer manipular intencionalmente os elementos expressivos, alterando a expressividade da performance.
No que se refere aos resultados obtidos na investigação dos aspectos musicais que mais influenciam na expressividade, pode-se concluir que todos considerados nessa pesquisa são relevantes para a amostra investigada, como mostram estudos anteriores (LISBOA; SANTIAGO, 2006; LOUREIRO, 2006; PELLON, 2008; TODD, 1992; WIDMER; GOEBL, 2004; WOODY, 2000). A dinâmica foi considerada como o aspecto que mais interfere na expressividade, confirmando as pesquisas (PALMER, 1997; WINTER; SILVEIRA, 2006) que a apontam como elemento a ser utilizado pelo intérprete com liberdade para a transmissão de características expressivas da performance. Os aspectos altura, articulação, intensidade e timbre também foram apontados como de alta influência, conforme era esperado. Quanto ao aspecto tempo, esperava-se que os ouvintes atribuíssem a ele uma maior influência na expressividade, por se tratar de um elemento subjetivo da partitura, assim como a dinâmica (Ross apud WINTER; SILVEIRA, 2006), cujas pequenas variações são em geral identificadas e modeladas visando uma maior expressividade (LOUREIRO, 2006; SUNDBERG; VERRILLO, 1980).

Considerando-se as respostas abertas dadas pelos estudantes para indicar livremente os aspectos fundamentais para a obtenção de uma performance expressiva, é interessante ressaltar que os itens "dinâmica" , "timbre", "intensidade" e "articulação" foram novamente apontados. Além disso, destaca-se o aparecimento do item "técnica" entre as respostas, o que comprova que, para alguns ouvintes, o desempenho técnico do performer é um dos aspectos mais visados na avaliação (OLIVEIRA; TOURINHO, 2003; SWANWICK, 2003), ainda que o foco esteja na expressividade. Ressalta-se também a presença do item "sentimento", que está relacionado ao impacto emocional que a música traz ao ouvinte (JUSLIN, 2001; 2004). GERLING et al. (2008) afirmam que no momento de escuta e apreciação musical é comum que o ouvinte relacione aspectos da peça ouvida a emoções.

Assim, pode-se então afirmar que foram atingidos os objetivos estabelecidos para essa pesquisa, que se propunha em apresentar considerações sobre 0 estudo de performances com o foco na comunicação e na percepção da expressividade, bem como chegar a conclusões que apontassem a relação entre a variação da expressividade e a preferência de performances pelos estudantes. Dessa forma, sugere-se que sejam realizados estudos futuros que abordem ouvintes não estudantes de música, a fim de comparar os trabalhos e investigar qual a influência da educação musical formal no julgamento da expressividade em performances. 


\section{Referências}

ANDREU, Roberto Cremades. Influencia de la educación formal e informal en las concepciones y gustos musicales de los Estudiantes del conservatorio profesional de música de Melilla. Melilla: Universidad de Granada, 2009.

BOYLE, J. David. Measurement and evaluation of musical experience. New York: Achirmer Books, 1987.

BRESIN, Roberto; BATTEL, Giovanni Umberto. Articulation strategies in expressive piano performance. Journal of New Music Research, v.29. 2000.p.211-224.

CANAZZA, Sergio; DE POLI, Giovanni; RODÃ, Antonio; VIDOLIN, Alvise. An abstract control space for communication of sensory expressive intentions in music performance. Journal of New Music Research, v.32, n.3, 2003.p.281-294.

DA SILVA, L. M. G.; BRASIL, V. V.; GUIMARÃES, H. C. O. C. P.; SAVONITTI, B. H. R. de A.; DA SILVA, M. J. P. Comunicação nãoverbal: reflexões acerca da linguagem corporal. Revista latino-americana de enfermagem, v.8, n.4. Ribeirão Preto: USP, 2000.p.52-58.

DA SILVA, Edna Lúcia; MENEZES, Estera Muszkat. Metodologia da pesquisa e elaboração de dissertação. 3. ed. rev. e atual. Florianópolis: Laboratório de Ensino a Distância da UFSC, 2001.

DE POLI, Giovanni; RODÀ, Antonio; VIDOLIN, Alvise. Note-by-Note Analysis of the influence of expressive intentions and musical structure in violin performance. Journal of New Music Research, v.27, n.3, 1998.p.293-321.

DE POLI, Giovanni. Methodologies for Expressiveness Modelling of and for Music Performance. Journal of New Music Research, v.33, n.3, 2004.p.189-202.

EMRICH, Ana Rita Oliari. BARRENECHEA, Lúcia Silva. A avaliação da performance musical: um estudo do processo de avaliação do ensino de instrumentos musicais. In: SEMINÁRIO NACIONAL DE PESQUISA EM MUSICA, 4., 2004, Goiânia. Anais eletrônicos... Disponivel em: <http://www.musica.ufg.br/mestrado/anais/anais\%20IV\%20Sempem/ artigos/artigo\%20Kamilla\%20Thais.pdf>. Acesso em: 9 mai. 2009.

FIREMAN, Milson Casado. A escolha de repertório na aula de violão como uma proposta cognitiva. Em Pauta, v.18, n.30. Porto Alegre: UFRGS, 2007.p.93-129.

FRANÇA, Cecilia Cavalieri. A natureza da performance instrumental e sua avaliação no vestibular em música. Opus, ano 8, n.7. São Paulo, 2001.

FRANÇA, Cecilia Cavalieri; SWANWICK, Keith. Composição, apreciação e performance na educação musical: teoria, pesquisa e prática. Em Pauta, v.13, n.21. Porto Alegre: UFRGS, 2002.p.5-41.

FRANÇA, Cecilia Cavalieri. Dizer o indizivel?: considerações sobre a avaliação da performance instrumental de vestibulandos e graduandos em música. Per Musi, v.10, Belo Horizonte, UFMG, 2004.p.31-48.

GALL, M.; GALL, J.; BORG, W. Educational Research: an Introduction. Boston: Allyn and Bacon, 2003.

GERLING, Cristina Capparelli; DOMENICl, Catarina; SANTOS, Regina Antunes Teixeira dos. Reflexões sobre interpretações musicais de estudantes de piano e a comunicação de emoções. Música Hodie, v.8, n.1. Goiânia: UFG, 2008.p.11-25.

HENTSCHKE, Liane. DEL BEN, Luciana. Aula de música: do planejamento e avaliação à prática educativa. In: Ensino de música: propostas para pensar e agir em sala de aula. São Paulo: Moderna, cap.11, p.176-189, 2003.

JOURDAIN, Robert. Música, cérebro e êxtase. Como a música captura nossa imaginação.Trad. de Sonia Coutinho. Rio de Janeiro: Objetiva, 1998.

JUSLIN, Patrick N. Communicating emotion in music performance: a review and theoretical framework. In: Music and emotion: theory and research. Oxford: Oxford University Press. cap.14, p.309-338, 2001.

JUSLIN, Patrick N.; PETRI, Laukka. Expression, perception, and induction of musical emotions: a review and a questionnaire study of everyday listening. Journal of New Music Research, v.33, n.3. 2004.p.217-238.

LISBOA, Christian Alessandro; SANTIAGO, Diana. A comparação de execuções de peças para piano do séc. XX com foco na transmissão de emoções. In: CONGRESSO DA ASSOCIAÇÃO NACIONAL DE PESOUISA E PÓS-GRADUAÇÃO EM MÚSICA, 15., 2005, Rio de Janeiro. Anais... Rio de Janeiro: ANPPOM, 2005, p.1196-1203.

LOUREIRO, Maurício. A pesquisa empírica em expressividade musical: métodos e modelos de representação e extração de informação de conteúdo expressivo musical. Opus, ano 12, n.12. Campinas, 2006.

OLIVEIRA, Alda; TOURINHO, Cristina. Avaliação da performance musical. In: Avaliação em música: reflexões e práticas. São Paulo: Moderna. cap1. p.13-28, 2003.

PALHEIROS, Graça Boal. Funções e modos de ouvir música de crianças e adolescentes, em

diferentes contextos. In: ILARI, Beatriz (Org.). Em busca da mente musical: ensaios sobre os processos cognitivos em música - da percepção à produção. Curitiba: Ed. da UFPR. cap 9, p.303-352, 2006.

PALMER, Caroline. Music performance. Annual Reviews of Psychology. v.48, n.1, 1997.p.115-138.

PELLON, Bernardo. A teoria do contorno no estudo da emoção em música. In: SIMPÓSIO DE COGNIÇÃO E ARTES MUSICAIS, 4., 2008, Paulistana. Anais eletrônicos... Disponivel em: <http://www.fflch.usp.br/dl/simcam4/downloads_anais/ SIMCAM4_Bernardo\%20Pellon.pdf> Acesso em: 6 abr. 2009.

QUADROS JR, João Fortunato Soares de. Preferencia de estilos musicales en estudiantes de educación secundaria en Brasil: El caso de la ciudad de Vitória. Melilla: Universidad de Granada, 2009. $146 f$. 
ROBATTO, Pedro. Questões interpretativas no concerto para clarineta e piano op.116 de Ernst Widmer. Ictus, n.5. Salvador, 2004.p.107-120.

SADIE, Stanley. Expressão. In: DICIONÁRIO GROVE DE MÚSICA: edição concisa. Rio de Janeiro: Jorge Zahar, 1994.p.306.

SANTOS, Adriana Moraes dos; CORVISIER, Fernando Crespo. Os pedais e suas aplicações na técnica pianística. In: SIMPÓSIO INTERNACIONAL DE INICIAÇÃO CIENTÍFICA DA UNIVERSIDADE DE SÃO PAULO, 15., 2005, São Paulo. Disponível em: $<$ http://www.usp.br/siicusp/Resumos/15Siicusp/156.pdf>. Acesso em: 20 nov. 2009.

SLOBODA, John A. A mente musical: a psicologia cognitiva da música. Trad. de Beatriz Ilari e Rodolfo Ilari. Londrina: EDUEL, 2008.

SUNDBERG, Johan; VERRILLO, Violet. On the anatomy of the ritard: a study of timing in music. Journal of the Acoustical Society of America, v.68. 1980, p.772-779.

SWANWICK, Keith. Ensinando música musicalmente. Trad. de Alda Oliveira e Cristinha Tourinho. São Paulo: Moderna, 2003.

THOMPSON, Sam. Determinants of listeners' enjoyment of a performance. Psychology of Music, v.35, n.1. 2007.p.20-36.

TODD, Neil P. McAngus. The dynamics of dynamics: a model of musical expression. Journal of the Acoustical Society of America, v.91 n.6. 1992.p.3540-3550.

TOURINHO, Cristina. Relações entre os critérios de avaliação do professor de violão e uma teoria de desenvolvimento musical. Salvador: Universidade Federal da Bahia, 2001, $236 f$.

WIDMER, Gerhard; GOEBL, Werner. Computational models of expressive music performance: the state of the art. Journal of New Music Research, v.33, n.3. 2004.p.203-216.

WINTER, Leonardo Loureiro; SILVEIRA, Fernando José. Interpretação e execução: reflexões sobre a prática musical. Per Musi, n.13. Belo Horizonte: UFMG, 2006.p.63-71.

WOODY, Robert H. Learning expressivity in music performance: an exploratory study. Research Studies in Music Education, v.14, n.1. Indiana, 2000.p.14-23.

João Fortunato Soares de Quadros Júnior é professor da Universidade Estadual do Maranhão (UEMA) desde 2011. Foi professor da Universidade Federal do Maranhão - UFMA (2010-2011) e da Faculdade de Música do Espírito Santo FAMES (2009-2010). Doutorando em Educação Musical pela Universidad de Granada (Espanha), possui mestrado em Música/ênfase em Educação Musical pela Universidade Federal da Bahia (UFBA) e é licenciado em Artes/ênfase em Música pela Universidade Estadual de Montes Claros (UNIMONTES). Publicou em 2009 o livro "Fatores de influência no processo de ensino-aprendizagem musical: o caso da Escola Pracatum", pela Editora Unimontes, em parceria com os doutores Oswaldo Lorenzo (Espanha) e Ana Cristina Tourinho (UFBA). Também em 2009, publicou o artigo "Conhecimento de estilo musical em estudantes espanhóis de Educação Secundária Obrigatória com diferentes origens culturais: análise desde a educação formal" na Revista da ABEM (n.21), em parceria com os doutores Oswaldo Lorenzo, Lucía Herrera e Roberto Cremades. Atualmente, desenvolve pesquisas sobre preferência musical em adolescentes.

Mikely Pereira Brito é licenciada em Música pela Faculdade de Música do Espírito Santo (FAMES). Publicou em 2010 o artigo denominado "A avaliação da expressividade na performance: um estudo de caso", no XIX Congresso Nacional da Associação Brasileira de Educação Musical. 